\title{
Mechanical Strength and Analysis of Fracture of Titanium Joining Submitted to Laser and Tig Welding
}

\author{
Ana Cláudia Gabrielli Piveta*, Andréia Affonso Barreto Montandon, \\ Weber Adad Ricci, Maurício Meirelles Nagle \\ Department of Social Dentistry, School of Dentistry, São Paulo State University - UNESP, \\ Araraquara, SP, Brazil
}

Received: October 3, 2011; Revised: June 14, 2012

This study compared the tensile strength and fracture mechanism of tungsten inert gas (TIG) welds in cylindrical rods of commercially pure titanium (cp Ti) with those of laser welds and intact samples. Thirty dumbbell-shaped samples were developed by using brass rods as patterns. The samples were invested in casings, subjected to thermal cycles, and positioned in a plasma arc welding machine under argon atmosphere and vacuum, and titanium was injected under vacuum/pressure. The samples were $\mathrm{X}$-rayed to detect possible welding flaws and randomly assigned to three groups to test the tensile strength and the fracture mechanism: intact, laser welding, and TIG welding. The tensile test results were investigated using ANOVA, which indicated that the samples were statistically similar. The fracture analysis showed that the cpTi samples subjected to laser welding exhibited brittle fracture and those subjected to TIG welding exhibited mixed brittle/ductile fracture with a predominance of ductile fracture with the presence of microcavities and cleavage areas. Intact samples presented the characteristic straightening in the fracture areas, indicating the ductility of the material.

Keywords: laser welding, TIG welding, titanium, prosthesis implant, mechanical strength, dental welding

\section{Introduction}

The loss of one or more teeth may be the beginning of a functional and aesthetic collapse that worsens oral health status, breaking the balance of the stomatognathic system. The development of implant dentistry and the use of biomaterials ${ }^{1,2}$ have enabled replacing teeth with osseointegrated implants that preserve the teeth adjacent to the anodontic space.

Titanium and its alloys stand out owing to their biocompatibility ${ }^{3-8}$ and biofunctionality; furthermore, they exhibit the essential mechanical, physical, and chemical properties, including low density, high mechanical strength, and corrosion resistance ${ }^{9,10}$. Another advantage of titanium implants is that only a single metal is used to manufacture the implant, which eliminates the potential for galvanic current between the implant and the metallic infrastructure of the dental prosthesis.

A fixed prosthesis supported by one or more implants will present a uniform distribution of forces with passive adaptation on the pillars ${ }^{11,12}$. While making prosthesis, some errors during the molding and/or casting phase may occur, which make it difficult to obtain passivity ${ }^{13,14}$. These errors may be corrected by welding methods such as brazing, which is the most common method in dentistry. However, brazing cannot be applied to commercially pure titanium (cp Ti) and alloys containing this material owing

*e-mail: anacrgpiveta@foar.unesp.br to its high reactivity with oxygen at high temperature ${ }^{21}$ and owing to the formation of a fine and adhering layer of oxide that determines the chemical properties and resistance to corrosion $^{7,9,10,15}$.

Among the various alternatives, tungsten inert gas (TIG) and laser welding under a shielding gas can be used to weld titanium and its alloys ${ }^{10,15-22}$.

Gas tungsten arc welding (GTAW) is a joining process in which the materials are heated with an electric arc established between a tungsten non-consumable electrode and the part to be welded. The electric arc forms by ionization of the gaseous medium and is accompanied by a bright light and reduction of heat. It is formed when two electrical current conductors, i.e., the tungsten electrode and the part to be welded, are brought close to each other. To avoid contamination by atmospheric gases, the surfaces to be welded and the electric arc are protected by an inert gas or inert gas mixture with or without the addition of a filler material ${ }^{15}$.

Laser welding employs pulses from a neodymium yttrium garnet (Nd:YAG) laser for periodic heating of the weld puddle at the energy peak of the incident laser beam, which causes casting and solidification of the puddle $2,14,23,24$. The welding speed is determined by the spot overlap, pulse repetition rate, and focal diameter of the beam. However, owing to the high power at the energy peak of the pulsed laser, the solidification time is reduced. 
Laser welding is one of the most commonly used welding methods in dentistry to join titanium and its alloys $^{2,4,24}$. However, the cost of the equipment is high, which contributes significantly to the final cost of the procedure.

Preliminary studies ${ }^{9,15,20,24,25}$ have shown that it is possible to use the TIG welding to join cp Ti in dentistry, which is advantageous since the equipment cost is lower than that of the laser welding equipment. Thus, the objective of this study was to compare the mechanical properties such as tensile strength and fracture mechanism of cp Ti samples welded using TIG and laser welding.

\section{Material and Methods}

Thirty samples were prepared in the shape of dumbbells in accordance with the specifications of the Technical Standard ASTM E $8 \mathrm{M}^{26}$ for metallic materials. Welding was carried out using a plasma arc welding machine (Rematitan, Dentaurum, Pforzheim, Germany) in vacuum and under Ar atmosphere using vacuum and pressure metal injection, allowing the metal to be cast over a fine layer of itself. Thus, after joining the metal, only the inside of the casting is injected into the casing mold, and the remaining "shell," which corresponds to the outside of the casting, remains in the upper compartment of the machine. This limits contamination of the metal.

After welding, the dumbbell-shaped samples were removed from the casing, separated from their sprues, and cleaned with aluminum oxide blasting to eliminate any tracks of surface refractory material.

All the samples were subject to X-ray analysis to identify flaws in the welding.

All samples were cut in half, aligned in the matrix, joined with acrylic resin (Duralay II, Reliance Dental Mfg. Co., Chicago, USA), and juxtaposed with no separation. Then, the samples were invested in the casing block (Rematitan Plus, Dentaurum, Pforzheim, Germany).

An inverter-powered TIG welding machine (AUTOGÊNIC JVM, São Paulo, Brazil) capable of producing a low electrical current for welding was used. The welding parameters were as follows: electrical current: $43 \mathrm{~A} \mathrm{dc}$ for $1 \mathrm{~s}$; pre- and post-Ar gas flow time: $5 \mathrm{~s}$; welding mode: $50 \%$; material: titanium; welding time: 3 s, electrode: tungsten rod with a diameter of $1 \mathrm{~mm}$ with sharpened tip in the shape of a pencil to concentrate heat while welding.

Laser welding was carried out using a Laser Braasel-Lasertech (Dentaurum) welding machine that is specific for dental applications and uses a Nd:YAG crystal as the laser source.

For laser welding, the samples were positioned on a Plexiglass matrix by juxtaposing and maintaining the position with the two contact halves aligned according to the horizontal marks used for positioning, without any space between them. This set was placed directly inside the welding machine chamber for welding.

Inside the chamber, under the Ar shielding atmosphere, 35-40 welding points were created on each side along the longitudinal section of the joint, with a voltage of $380 \mathrm{~V}$ and a pulse duration of $8 \mathrm{~ms}$. In this section, the welding points overlapped by approximately $2 / 3$ of their surfaces in order to obtain a full and deep weld.
The laser and TIG welding processes were carried out under Ar atmosphere, and no thermal treatment was conducted after welding.

The samples were adapted to a device and positioned in a universal testing machine (EMIC). The load cell applied had a maximum capacity of $2000 \mathrm{Kgf}$, and the speed of the actuator in the test was $1.0 \mathrm{~mm} / \mathrm{min}$. Ten specimens were tested under each set of experimental conditons, laser welding, TIG welding e control group. (gc: control group). After the tensile tests, the fracture surfaces were subjected to qualitative analysis by scanning electron microscopy (SEM) at magnifications of 35, 200, and 1000 times.

The analysis of variance (ANOVA) was used to compare the average of tensile strength (Mpa) among the different groups, after assisted the pressuposted of normality (Shapiro Wik: $\mathrm{p}=0.0 .093$ to 0.762 ) and homoscedaticity (Levene $\mathrm{F}=1.887, \mathrm{p}=0.171)$. Level of significance was $5 \%$.

\section{Results}

The average and standard deviation (SD) of control group tensile strength was $476.1(\mathrm{SD}=55.0)$, the laser welding group 494.1 (SD = 64.1) and the group TIG welding 523.6 ( $\mathrm{SD}=122.5)$. Descriptive statistics of tensile strength are summarized in Table 1.

There was no statistical significance for the type of welding method used.

Figures 1-3 show the SEM micrographs of the fracture surfaces of the samples not subjected to welding, control group. The figures show the occurrence of ductile/brittle fracture, with a predominance of a ductile fracture and the presence of conical equiaxial microcavities and cleavage areas known as "dimples."

The control group exhibited an irregular fracture surface related to the $\alpha$ (hcp) phase.

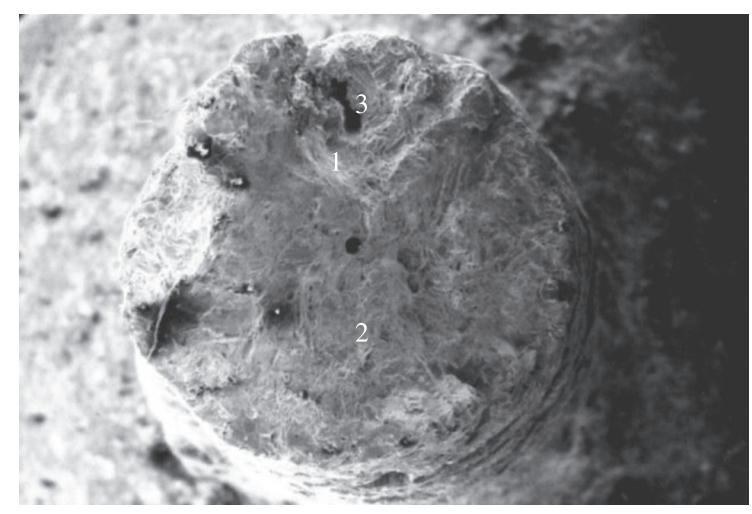

Figure 1. SEM micrograph of fracture surface of control group cpTi at $35 \mathrm{X}$ magnification: 1 .ductile; 2.brittle;3.microcavity.

Table 1. Descriptive statistics of tensile strength of ANOVA.

\begin{tabular}{ccrccc}
\hline $\begin{array}{c}\text { Source of } \\
\text { variance }\end{array}$ & DF & $\begin{array}{c}\text { Sum of } \\
\text { square }\end{array}$ & $\begin{array}{c}\text { Mean } \\
\text { square }\end{array}$ & $\begin{array}{c}\text { F } \\
\text { Value }\end{array}$ & $\begin{array}{c}\text { P } \\
\text { Value }\end{array}$ \\
\hline Group & 2 & 11467.3 & 5733.6 & 0.777 & 0.47 \\
Residue & 27 & 199218.5 & 7378.5 & & \\
Total variance & 30 & 7649411.5 & & & \\
\hline
\end{tabular}


Figures 4-6 showed SEM micrographs of the fracture surfaces of cp Ti samples with laser welding. The figures show ductile/brittle fracture, with a predominance of brittle fracture. The microcavities are more elongated, with cleavage areas, which may be attributed to the contribution of shear.

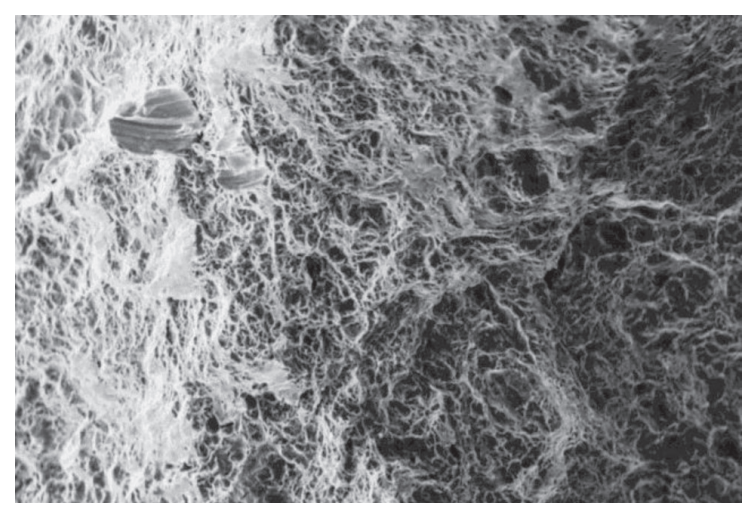

Figure 2. SEM micrograph of fracture surface control group cpTi at $200 \mathrm{X}$ magnification.

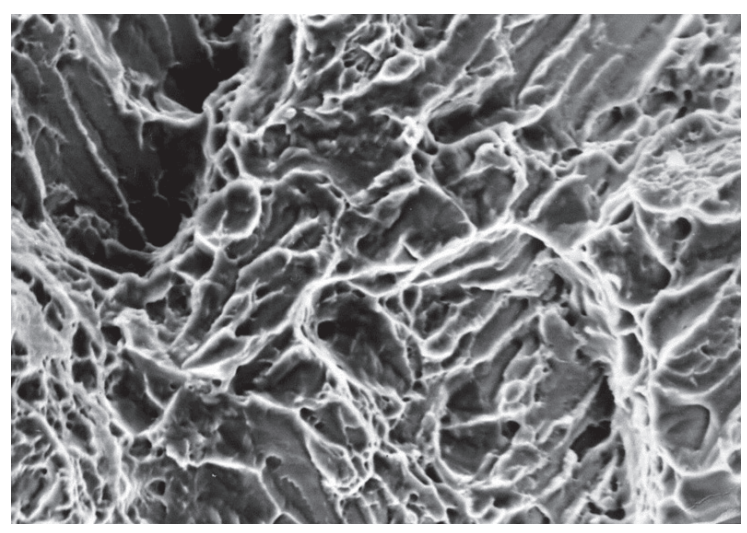

Figure 3. SEM micrograph of fracture surface control group Ti sample at 1000X magnification

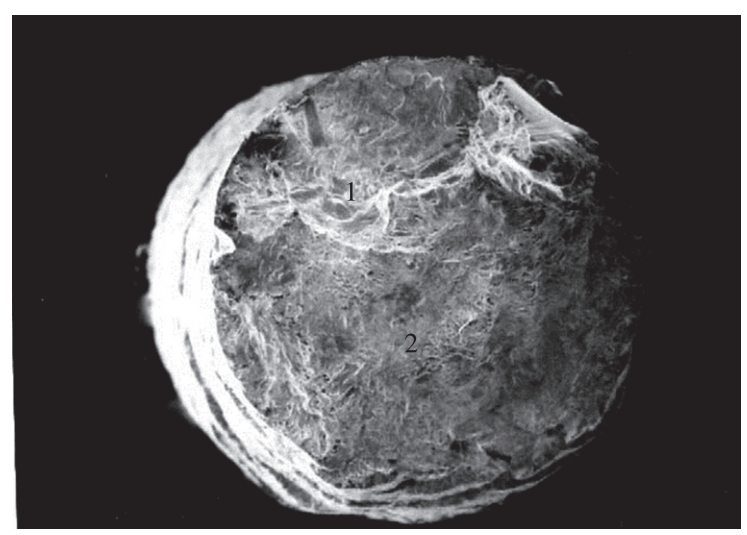

Figure 4. SEM micrograph of fracture surface of laser-welded cpTi sample at $35 \mathrm{X}$ magnification: 1 ductile fracture, 2. brittle fracture
Figures 7-9 show that fracture surfaces of the cpTi with laser welding are flat and have shallow "dimples," proving the ductility of the cp Ti. The lack of penetration in laser welding prevented complete fusion of the welded parts in the two specimens used in this study.

Figures 10-16 showed the SEM micrographs of the fracture surfaces of the cpTi with TIG welding. In Figure 11, the presence of ductile/fragile fracture can be observed, with the predominance of ductile fracture and some "dimples" characterizing the degree of ductility of the material.

Figure 10 shows that ductile/brittle fracture occurred with a predominance of brittle fracture owing to the presence of welding defects, which make it easier to spread cracks (cleavage areas).

As in the case of the samples with laser welding, the samples with TIG welding exhibited defects such as pores and, in only one smaple, the lack of joint formation (Figure 16).

\section{Discussion}

In the welded samples with lower tensile strength, large pores or a lack of weld penetration was identified. Some fractured at the weld bead/base metal interface; however,

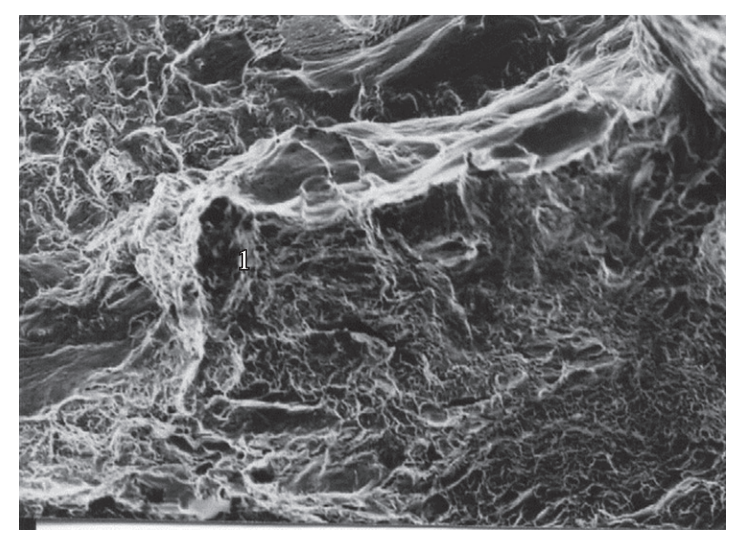

Figure 5. SEM micrograph of fracture surface of laser-welded cpTi sample at 200X magnification: 1. Elongated microcavities

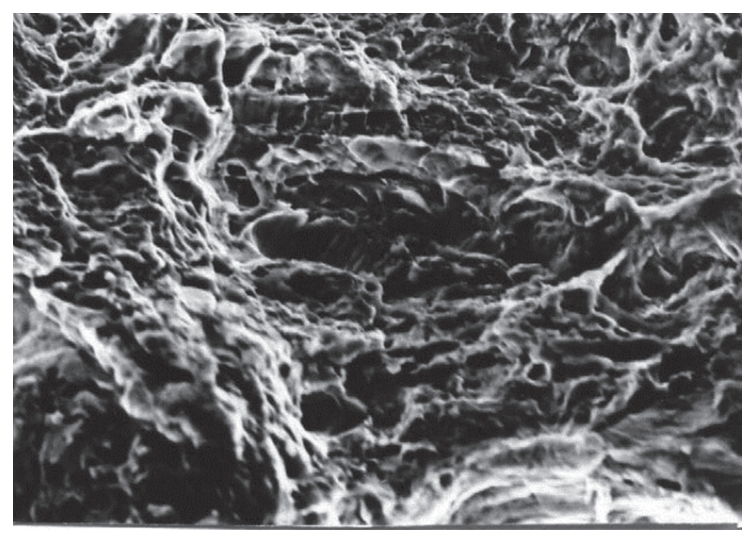

Figure 6. SEM micrograph of fracture surface of laser-welded cpTi sample at $1000 \mathrm{X}$ magnification 
a majority fractured completely in the base metal. This indicates that the weld is stronger or of equal strength to the base metal. The intact samples were weaker than those subjected to welding, proving the ductile nature of $\mathrm{cp} \mathrm{Ti}$.

For laser welding of $\mathrm{cp} \mathrm{Ti}$, the tensile strengths reported by Taylor et al. ${ }^{17}$ and Sjogren et al. ${ }^{4}$ were superior to those found in this study (454 MPa). However, the values reported by Berg et al. ${ }^{22}$, Neo et al. ${ }^{6}$, and Chai \& $\mathrm{Chou}^{9}$ were similar to those found in this study.

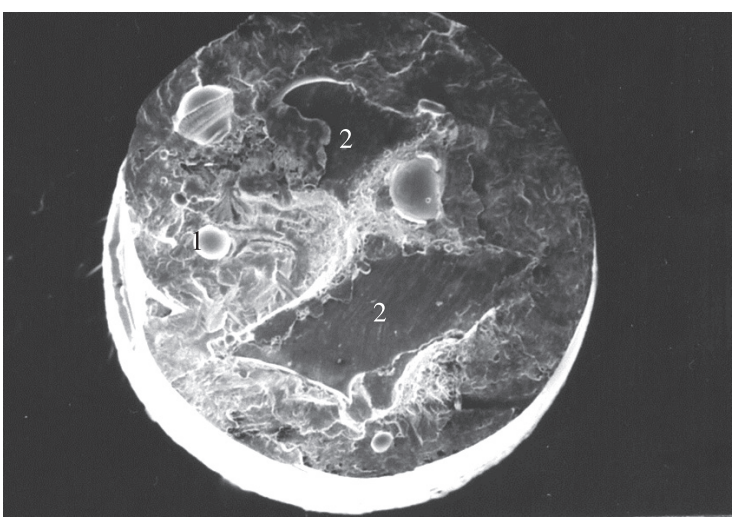

Figure 7. SEM micrograph of fracture surface of laser-welded cpTi sample at $35 \mathrm{X}$ magnification.

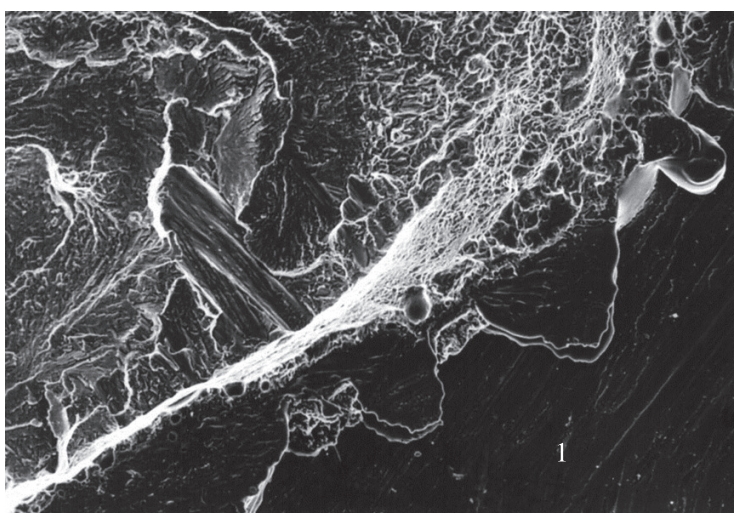

Figure 8. SEM micrograpf of fracture surface laser-welded cpTI sample at 200X magnification: 1. Area without joint.

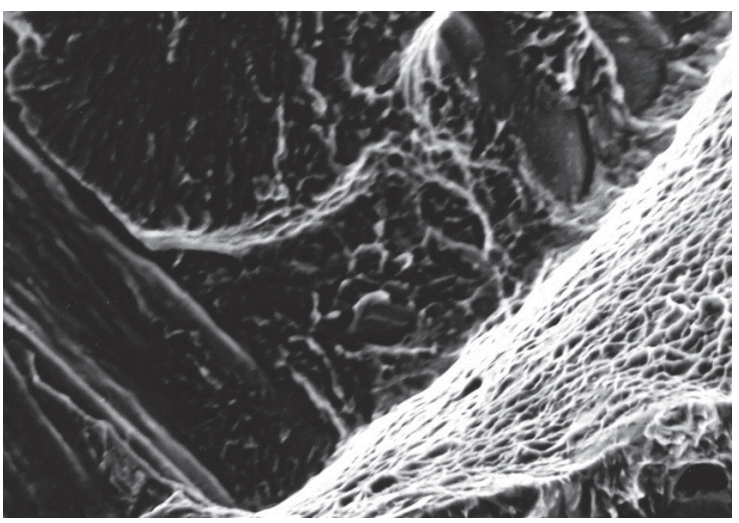

Figure 9. SEM micrograph of fracture surface of laser-welded cpTi sample at 1000X magnification
It has been verified that intact $\mathrm{cp}$ Ti has a tensile strength within the range of values established for this material. It can be stated that the results of this study (476 MPa) are similar to those in the literature, particularly those reported by Neo et al. ${ }^{6}$. By contrast, the values reported by Sjogren et al. ${ }^{6}$, Taylor et al. ${ }^{17}$, and Chai \& $\mathrm{Chou}^{9}$ are larger than those reported by other researchers.

When comparing the tensile strengths of the TIG-welded joints, the results obtained in this study $(526 \mathrm{MPa})$ are larger than those reported by Wang \& Welsh ${ }^{15}$.

There are two types of fractures: ductile and brittle. Ductile fracture occurs by spreading as a result of the intense plastic deformation of the metal located along the crack entrance. A completely ductile fracture presents a gray irregular surface. A brittle fracture is characterized by the movement of cracks involving very small plastic deformation of the metal. Cleavage fracture is completely brittle and presents facets that reflect light.

Figure 1 shows a decrease in the section area of the intact samples (control group) after tensile testing when compared with the samples subjected to welding. This is attributed to the occurrence of plastic deformation and the ductility characteristics of $\mathrm{cp} \mathrm{Ti} i^{1,12,15}$. The samples that were subjected to welding had higher tensile strengths owing to the change in the metallurgical structure in the weld.

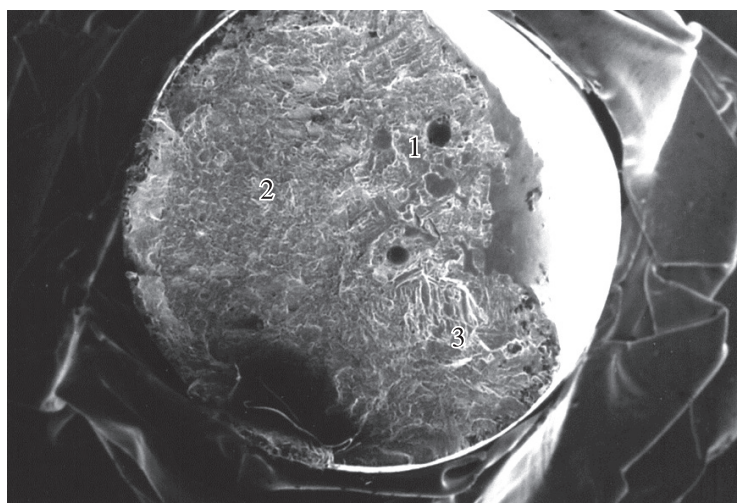

Figure 10. SEM micrograph of fracture surface of TIG-welded $\mathrm{cp}$ Ti sample at $35 \times$ magnification. 1. pores, 2. ductile fracture, 3 . brittle fracture.

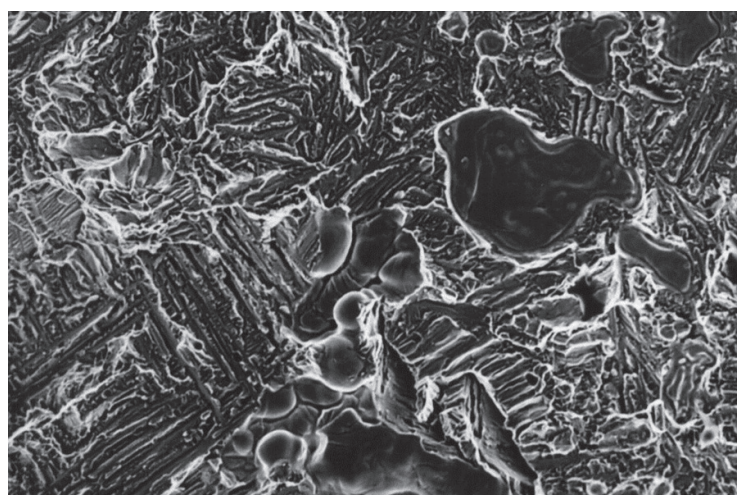

Figure 11. SEM micrograph of fracture surface of TIG-welded cp Ti sample at $200 \times$ magnification. 
All samples subjected to laser welding exhibited brittle fracture (Figure 4) and a decrease in ductility in the welded region. Such increase in hardness for cp Ti may decrease the fatigue strength ${ }^{19,20}$ and may be related to the presence of impurities and changes in the grain size ${ }^{16}$ and depend on the cooling conditions of the weld ${ }^{10,18,20}$.

In this study, the most frequent defects found on the fracture surfaces were pores in samples subjected to TIG welding and a lack of penetration in those subjected to laser welding. Similar findings were also reported by Wang \& Welsh ${ }^{15}$, Taylor et al. ${ }^{17}$, and Sjogren et al. ${ }^{4}$.

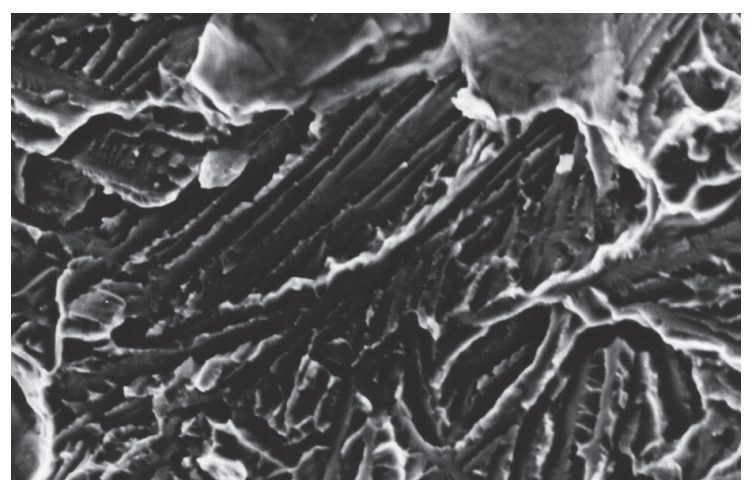

Figure 12. SEM micrograph of fracture surface of TIG welded cp Ti sample at $1000 \times$ magnification.

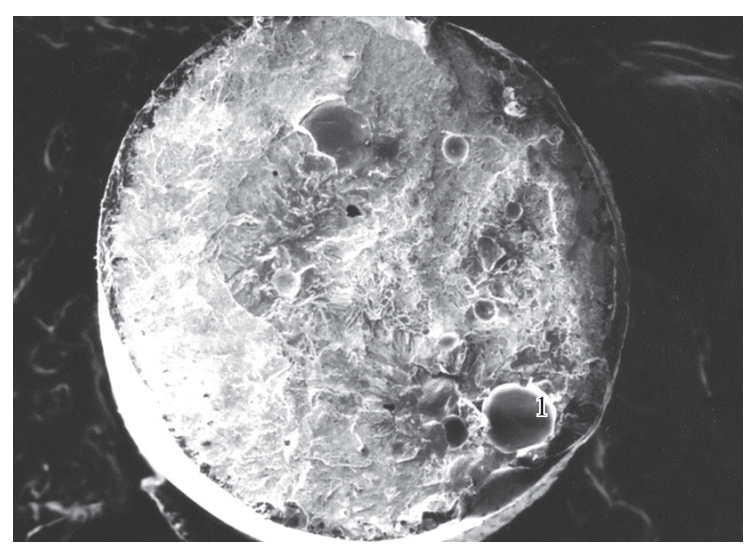

Figure 13. SEM micrograph of fracture surface of TIG-welded cp Ti sample at $35 \times$ magnification: 1 . pores.

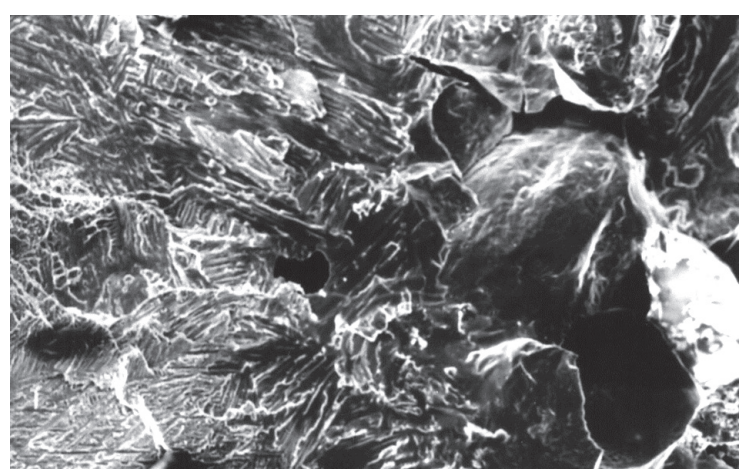

Figure 14. SEM micrograph of fracture surface of TIG-welded cp Ti sample at $1000 \times$ magnification.
Pores produce stress concentration, which facilitates the spreading of cracks $^{16}$ in samples subjected to both laser welding as well as TIG welding. This may be linked to trapping Ar gas $1,7,16,19$, which compromises the strength of the weld ${ }^{9,16,17,22}$. However, Namoto et al. ${ }^{18}$ carried out cp Ti welding without adding metal and verified that a porosity variation in the range of $0.01 \%-0.17 \%$ does not affect the strength of the weld.

In Figures 7, 8, and 9, most of the central area was not joined, which contributed to a brittle fracture and a tensile strength of $139.8 \mathrm{MPa}$.

Incomplete joints produced by laser welding have considerable impact on the final prosthesis. Limited weld depth may also compromise the machining and polishing of prosthetic parts. Nevertheless, regardless of the welding technique used, in dentistry, the preparations before welding a metallic part must carried out with caution, and it is important that for welding performed without adding metal, the parts to be welded are juxtaposed ${ }^{2,15,12,18,25}$.

In laser welding, the use of welding points on each side of the longitudinal section of the joint prevents an incomplete connection and when linked to multiple radiation pulses ${ }^{7,23}$ and welding parameter variations ${ }^{16}$, the penetration and tensile strength of the weld significantly increase ${ }^{27}$ essencial requeriments of a dental weld.

Laser welding produces a smaller heat affected zone ${ }^{9,12}$ and lower distortion to the weld compared with the TIG method $^{12,15}$. Laser welding has two adjustable parameters:

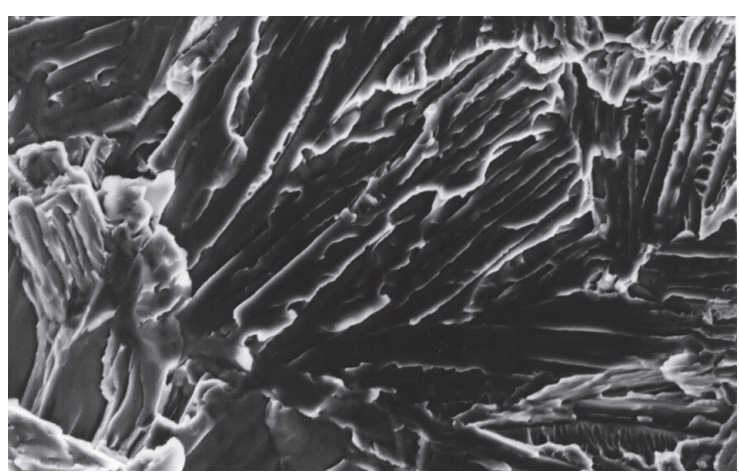

Figure 15. SEM micrograph of fracture surface of TIG-welded cp Ti sample at 1000× magnification.

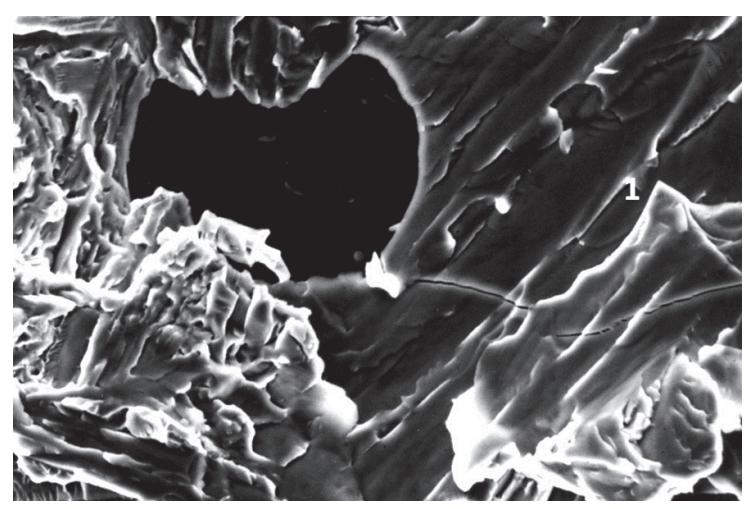

Figure 16. SEM micrograph of fracture surface of TIG-welded cp Ti sample at $1000 \times$ magnification. 1 . Absence of joint formation. 
voltage and pulse duration ${ }^{11}$. Voltage controls the welding energy: an increase in voltage leads to an increase in the weld depth. Pulse duration influences the diameter of the welding point, and an increase in the pulse duration increases the delivery of heat to the base metal ${ }^{2,9}$.

Previous studies ${ }^{4,7,9}$ on laser-welded titanium structures for use in dentistry have shown that this method is efficient and can be used near the aesthetic cover of prosthetic parts ${ }^{8}$. However, the literature does not have a protocol with regards to the parameters used in this welding method for dental prosthetics $^{11}$.

In the TIG process, welding can be accomplished with or without adding metal, and the operational variances are the arc length, electrical current, welding speed, and shielding gas flow ${ }^{25}$. The longer the arc is, the shallower and wider the weld beads will be; the higher the current, the larger the penetration and the width of the welded area. An increase in the welding speed decreases the width and penetration of the weld bead. The shielding gas flow rate also changes the quality of the weld: a very low flow rate results in insufficient protection, which favors oxidation of the part, and high gas flow rate does not cause problems, but increases the cost of the procedure.

Both laser and TIG welding depend not only on physical parameters related to the machine but also on the experience, dexterity, and foresight of the operator ${ }^{2,25}$. As such, it is evident that the results obtained in this study are not completely consistent with those found in the literature owing to the different welding parameters used, which result in discrepancies in the metal structure and, consequently, changes to mechanical properties.

According to previous studies $5,6,12,15,17,25$, titanium welding under Ar atmosphere is very efficient and yields

\section{References}

1. Yamazoe J, Nacagawa M, Matono Y, Takeuchi A and Ishikawa $\mathrm{K}$. The development of Ti alloys for dental implant with high corrosion resistance and mechanical strength. Dental Materials Journal. 2007; 26:260-67. PMid:17621943. http://dx.doi. org/10.4012/dmj.26.260

2. Bertrand C and Poulon-Quintin A. Proposals for optimization of laser welding in prosthetic dentistry. Journal of Prosthodontics. 2009; 19:69-76. PMid:19780906. http:// dx.doi.org/10.1111/j.1532-849X.2009.00523.x

3. Hruska AR and Borelli P. Quality criteria for pure titanium casting, laboratory soldering, intraoral welding, and a device to aid in making uncontaminated castings. Journal of Prosthetic Dentistry. 1991; 66:561-5. http://dx.doi. org/10.1016/0022-3913(91)90524-Z

4. Sjogren G, Andersson M and Bergman M. Laser welding of titanium in dentistry. Acta Odontologica Scandinavica. 1988; 46:247-53. http://dx.doi. org/10.3109/00016358809004774

5. Oda Y and Okabe T. Effect of corrosion on the strength of soldered titanium and Ti-6Al-4V alloy. Dental Materials. 1996; 12:167-72. http://dx.doi.org/10.1016/ S0109-5641(96)80016-9 accurate lab results ${ }^{13}$. However, there is the need for future research to develop a protocol and parameters for the TIG welding technique.

One of the great advantages of the laser and TIG welding processes is in the possibility of welding without adding welding metal and the lack of need for using base metal as an addition metal, which decreases the likelihood of corrosion and increases the resistance of the welded joint $t^{1,5,15,17,21}$. These are core welding requirements for use in the welding of prosthetic parts used in the mouth. However, the literature does not contain studies with TIG welding applied to dentistry and oral rehabilitation as it is still a method under development for this purpose.

According to the results obtained in this study, a TIG weld may be a substitute method for laser, which will reduce the cost of the prosthetic work significantly. Therefore, more research is necessary with regard to the TIG welding method, particularly with respect to the applied welding parameters.

\section{Conclusions}

There is no statistically significant difference in tensile strength between the samples subjected to the laser, TIG methods and control group.

The laser-welded samples had a higher number of welding flaws such as lack of penetration and microcavities. Fracture analysis of the laser-welded regions indicated brittle fracture, and the TIG welds exhibited mixed ductile/brittle fracture, with the predominance of ductile fracture in the presence of microcavities and cleavage areas.

The control group exhibited a flat fracture surface owing to the ductile behavior of titanium.
6. Neo TK, Chai J, Gilbert JL, Wozniak WT and Engelman MJ. Mechanical properties of titanium connectors. International Journal of Prosthodontics. 1996; 9:379-93. PMid:8957877.

7. Watanabe I, Watkins JH, Nakalimah, Atsuta M and Okabe T. Effect of pressure difference on quality of titanium casting. Journal of Dental Research. 1997; 47:473-81.

8. Galo R, Ribeiro RF, Rodrigues RCS, Pagnano VO and Mattos MGC. Effect of laser welding on the titanium composite tensile bond strength. Brazilian Dental Journal. 2009; 20(5):403-409. PMid:20126909. http://dx.doi. org/10.1590/S0103-64402009000500008

9. Chai $\mathrm{T}$ and Chou CK. Mechanical properties of laser welded titanium joints under different conditions. Journal of Prosthetic Dentistry. 1998; 79:477-83. http://dx.doi.org/10.1016/ S0022-3913(98)70165-9

10. Orsi IA, Raimundo LB, Bezzon OL, Nóbilo MAA, Kuri SE, Rovere CAD et al. Evaluation of anodic behavior of commercially pure titanium in tungsten inert gas and laser welds. Journal of Prosthodontics. 2011; 20:628-631. PMid:21972796. http://dx.doi.org/10.1111/j.1532-849X.2011.00771.x

11. Silveira-Junior CD, Neves FD, Fernandes-Neto AJ, Prado CJ and Simamoto-Junior. Influence of different tightening forces before laser welding to the implant/framework fit. Journal of Prosthodontics. 2009; 18:337-341. PMid:19210612. http:// dx.doi.org/10.1111/j.1532-849X.2008.00418.x 
12. Nuñes-Pantoja JMC, Vaz LG, Nóbilo MAA and Mesquita MF Fatigue performance of joints executed in pure titanium structures with several diameters. Dental Materials Journal. 2011; 30(6):887-893. http://dx.doi.org/10.4012/ dmj.2011-112

13. Tiossi R, Falcão-Filho H, Aguiar Junior FA, Rodrigues RC, Mattos MGC and Ribeiro RF. Modified section method for laser-welding of ill-fitting cp $\mathrm{Ti}$ and $\mathrm{Ni}-\mathrm{Cr}$ alloy one-piece cast implant-supported frameworks. Journal of Oral Rehabilitation. 2010; 37:359-363. PMid:20149062. http:// dx.doi.org/10.1111/j.1365-2842.2010.02063.x

14. Aguiar Junior FA, Tiossi R, Rodrigues RC, Mattos MGC and Ribeiro RF. An alternative section method for casting and posterior laser welding of metallic frameworks for an implant-supported prosthesis. Journal of Prosthodontics. 2009; 18:230-234. PMid:19141050. http:// dx.doi.org/10.1111/j.1532-849X.2008.00405.x

15. Wang RR and Welsch GE. Joining titanium materials with tungsten inert gas welding, Laser welding, and infrared. Journal of Prosthetic Dentistry. 1995; 74:521-30. http://dx.doi. org/10.1016/S0022-3913(05)80356-7

16. Liu J, Watanabe I, Yoshida K and Astuta M. Joint strength of laser-welded titanium. Dental Materials. 2002; 18:143-48. http://dx.doi.org/10.1016/S0109-5641(01)00033-1

17. Taylor JC, Hondrum OS and Prasad A. Effects of joints configuration for the arc welding of cast Ti-6Al-4V alloy rods in argon. Journal of Prosthetic Dentistry. 1998; 79:291-97. http://dx.doi.org/10.1016/S0022-3913(98)70240-9

18. Nomoto R, Takayama Y, Tsuchida F and Hiroyuki N. Non-destructive three-dimensional evaluation of pores at different welded joints and their effects on joints strength. Dental Materials. 2010; 26:e246-e252. PMid:20828805. http:// dx.doi.org/10.1016/j.dental.2010.08.006
19. Nuñes-Pantoja JMC, Vaz LG, Nóbilo MAA, Henriques GEP and Mesquita MF. Effects of laser-weld joint opening size on fatigue strength of Ti-6Al-4V structures with several diameters. Journal of Oral Rehabilitation. 2011; 38:196-201. PMid:20678101. http://dx.doi.org/10.1111/j.1365-2842.2010.02140.x

20. Roggensack M, Walter MH and Boining KW. Studies on Laser and plasma welded titanium. Dental Materials.1993; 9:104-07. http://dx.doi.org/10.1016/0109-5641(93)90084-4

21. Schneider R. Full mouth restoration on dental implants utilizing titanium laser-welded frameworks. Journal of Esthetic and Restorative Dentistry. 2009; 21:215-228. PMid:19689718. http://dx.doi.org/10.1111/j.1708-8240.2009.00265.x

22. Berg E, Wagner WC, Davik G and Dootze R. Mechanical properties of laser-welded cast and wrought titanium. Journal of Prosthetic Dentistry. 1995; 74:250-7. http://dx.doi. org/10.1016/S0022-3913(05)80131-3

23. Shimakura M, Yamada S, Takeuchi M, Miura K and Ikeyama J. Influence of irradiation conditions on the deformation of pure titanium frames in laser welding. Dental Materials Journal. 2009; 28(2):243-247. PMid:19496406. http://dx.doi. org/10.4012/dmj.28.243

24. Rocha R, Pinheiro AL and Villaverde AB. Flexural strength of pure Ti, Ni-Cr and Co-Cr alloys submitted to Nd:YAG Laser ou TIG welding. Brazilian Dental Journal. 2006; 17:20-3. http:// dx.doi.org/10.1590/S0103-64402006000100005

25. Hart $\mathrm{CN}$ and Wilson PR. Evaluation of welded titanium joints used with cantilevered implant-supported prostheses. Journal of Prosthetic Dentistry. 2006; 96:25-32. PMid:16872927. http:// dx.doi.org/10.1016/j.prosdent.2006.05.003

26. American Society for Testing and Materials - ASTM. Mechanical Testing, Annual Book. West Conshohocken: ASTM; 1997. p. 1-8. 